\title{
Development and validation of a prognostic nomogram for predicting the survival of HIV/AIDS adults who received antiviral treatment: a cohort between 2003 and 2019 in Nanjing
}

\author{
Fangfang Jiang \\ Nanjing Medical University \\ Yuanyuan $\mathrm{Xu}$ \\ Nanjing municipal center for disease control and prevention \\ Li Liu \\ Nanjing municipal center for disease control and prevention \\ Kai Wang \\ Nanjing Medical University
}

Lu Wang

Chinese Center For Disease Control and Prevention

\section{Gengfeng Fu}

Jiangsu Center for Disease Control and Prevention

\section{Liping Wang}

Key Laboratory of Surveillance and Early-warning on Infectious Disease, Chinese Center for Disease Control and Prevention

\section{Zhongjie Li}

Key Laboratory of Surveillance and Early-warning on Infectious Disease, Chinese Center for Disease Control and Prevention

Junjie Xu

China Medical University

Hui Xing

Chinese Center For Disease Control and Prevention

Ning Wang

Chinese Center For Disease Control and Prevention

\section{Zhengping Zhu}

Nanjing municipal center for disease control and prevention

\section{Zhihang Peng ( $\square$ zhihangpeng@njmu.edu.cn )}

Nanjing Medical University 


\section{Research Article}

Keywords: HIV/AIDS, Antiviral treatment, Prognostic model, Nomogram

Posted Date: March 3rd, 2021

DOI: https://doi.org/10.21203/rs.3.rs-197435/v1

License: (c) (i) This work is licensed under a Creative Commons Attribution 4.0 International License. Read Full License 


\section{Abstract \\ Background}

Although great achievements have been made since free antiviral treatment (ART) was available, an intime and accurate prediction of survival for people living with HIV (PLHIV) is still needed for effective management. We aimed to establish an effective prognostic model to forecast the survival probability of PLHIV after ART.

\section{Methods}

The participants enrolled were from a follow-up cohort between 2003 and 2019 in Nanjing from Nanjing AIDS Prevention and Control Information System. The nested case-control study was employed with HIVrelated death, and propensity-score matching (PSM) approach was applied at a ratio of 1:4 to allocate the patients. Univariate and multivariate Cox hazards analyses were used based on the training set to determine the risk factors. The discrimination was qualified using the area under the curve (AUC) and concordance index (C-Index). The calibration was evaluated using the calibration curve. The clinical benefit of prognostic nomogram was assessed by decision curve analysis (DCA).

\section{Results}

Predictive factors including CD4 cell count (CD4), body mass index (BMI) and food blood glucose (GLU) were determined and contained in the nomogram. In the training set, AUC and C-index ( $95 \% \mathrm{Cl})$ were 0.826 and $0.793(0.740,0.846)$, respectively. The model of validation set still revealed good discrimination with an AUC and a C-index $(95 \% \mathrm{Cl})$ of 0.750 and $0.776(0.711,0.839)$. The calibration curve also exhibited a high consistency in predicting the survival of PLHIV (especially in the first three years after starting ART). Moreover, DCA demonstrated that the nomogram was clinically beneficial.

\section{Conclusion}

The nomogram is effective and accurate in forecasting the survival rate of PLHIV, and therefore accessible for medical workers in health administration.

\section{Introduction}

Over the past 30 years, HIV has become a major challenge to global public health ${ }^{[1]}$. Since 2003, when China launched free antiviral treatment (ART), great achievements have been made in improving the patients' survival and quality of life, such as recovering their CD4 + T lymphocytes count, lowering viral load (HIV RNA) and decreasing HIV transmission rate ${ }^{[2]}$. Nevertheless, the poor prognosis for people 
living with HIV (PLHIV) after ART is still worthy of concern ${ }^{[3-4]}$. Therefore, an in-time and accurate prediction of death risk for PLHIV is essential for clinicians and health care providers to perform effective PLHIV management.

Studies have shown that CD4 + T lymphocytes (CD4), CD8 + T lymphocytes (CD8), and viral load (HIV RNA) before treatment are closely associated with the mortality of PLHIV ${ }^{[5-13]}$. Clinical indicators are reported to have a close association with death risk of PLHIV ${ }^{[5,7-16]}$. Some laboratory indicators, such as hemoglobin (HB), platelet-related indexes, are also related to the progression and mortality of HIVassociated diseases after ART ${ }^{[3,17-23]}$.

Since the combination of several independent indicators, rather than a single predictive factor, is more likely to improve the predictive performance, several scoring systems based on the multiple risk factors have been proposed to forecast the mortality of PLHIV. However, there still lacks a widely-held effective scoring system to predict the survival probability of ART-treated PLHIV.

In recent years, the clinical prediction model, a multi-factor model to estimate the probability of catching a disease or the probability of an outcome event, has been used extensively in medical diagnosis and treatment, prognosis management of patients and public health resource allocation, contributing greatly to public health. To establish a risk score system, we followed the recommendation of Transparent Reporting of a multivariable prediction model for Individual Prognosis or Diagnosis (TRIPOD) ${ }^{[24]}$. Nomogram, as a more convenient and advanced clinical prediction model, is widely used to analyze prognosis ${ }^{[25]}$. Although previous studies have established prognosis nomogram models to assess ART survival probability, the predictive performance fails to meet the expectation. For example, the model by Margaret et al. ${ }^{[26]}$ has a concordance index (C-Index) of 0.75 (95\% Cl: $\left.0.74-0.81\right)$ in the training set and a C-Index of 0.69 (95\% Cl: $0.59-0.77)$ in the validation set.

This model is relatively satisfactory, but far from excellent.

Few prognosis models constructed for PLHIV after ART present satisfying discrimination and calibration. In the model established by Hou et al. ${ }^{[27]}$, the C-Indexes are as high as 0.91 (95\% Cl: $\left.0.86-0.97\right)$ in the training set and 0.92 (95\% Cl: 0.82-1.00) in the validation set. The patients involved were randomly split into a training set and a validation set. In case of small development sample size, the development data could not be fully utilized.

In the present study, to build a simple and effective prognostic model to forecast the survival probability of PLHIV after ART, nested case-control study was employed with HIV-related mortality events, and propensity-score matching (PSM) approach was applied at a ratio of 1:4 to allocate the patients. To make the model more reliable and robust, bootstrap was used for internal validation. The discrimination and calibration of the model were evaluated based on the training set and validation set. Decision curve analysis (DCA) was also used to evaluate the performance of prediction model. The prognostic model was displayed by a nomogram. 


\section{Material And Methods \\ Study design}

The data used in this study were extracted from patients who received ART between 2003 and 2019 from Nanjing AIDS Prevention and Control Information System (AIDS-PCIS). All patients received a free combination antiviral treatment (CART) containing at least three antiviral medicines. The follow-up started after treatment initiation and the participants were visited every three months. The observation end point was December 31, 2019, and the outcome was death. The survival time was defined as the duration from ART initiation to death or December 31,2019. The inclusion criteria included: 1) living in Nanjing; 2) being visited at least once; 3 ) being over 18 years old when ART started; 4 ) having complete laboratory test data before starting ART.

At the end of the observation, 4573 patients met the inclusion criteria, and a total of 120 patients died from HIV/AIDS-related diseases during the follow-up.

\section{Data collection}

Demographic data and clinical information were retrieved from face-to-face surveys at the patients' enrollment or extracted from their medical records using a structured questionnaire designed specifically for AIDS-PCIS. The information included the date of birth, gender, height, weight, marital status, infection route and WHO clinical stage. The age of the patient was calculated from the date of birth to the date of starting ART. Body mass index (BMI) was calculated using the following formula: $\mathrm{BMI}=$ weight $(\mathrm{kg}) /$ (height $(m)$ * height $(m)$ ).

The laboratory testing information was obtained from the Nanjing Center for Disease Control and Prevention (CDC) or local hospitals. The laboratory testing indicators included CD4, white blood cell (WBC), blood platelets (PLT), HB, serum creatinine (CR), triglycerides (TG), serum total cholesterol (TC), fasting blood glucose (GLU), aspartate aminotransferase (AST), alanine aminotransferase (ALT), total bilirubin (TBIL). All these laboratory tests were carried out by the trained technical personnel strictly following clinical guidelines at each visit in the central laboratory of local hospitals or Nanjing CDC.

Routine blood biochemical indexes, such as TG, TC, GLU, CR, AST, ALT, and TBIL, were measured using a Beckman AU5800 automatic biochemical analyzer (Beckman COULTER K., Japan). Other indexes including WBC, HB and PLT were evaluated by Sysmex Xe-2100 automatic blood cell analyzer (Sysmex Corporation, Japan). CD4 was determined by the BD FACSCalibur flow cytometer (Becton Dickinson Corporation, USA).

\section{Statistical analysis}

\section{Data processing}


Since the prediction model is based on a multi-factor regression model, there is no simple method to estimate the sample size. When the number of predictors is much larger than the observations of outcome, overfitting may occur. Previous literature showed that in the conservative estimation, one prediction factor requires at least 10 effective outcomes. In this study, there were 120 cases with effective outcomes, so the number of predictors should be no more than 12 .

Since directly dropping the observation with missing values might not only lead to selection bias, but also decrease the power of a test, missing value imputation was applied to obtain suitable values by employing the values of other variables before data analysis. The results were listed in Fig. 1. A sensitivity analysis was carried out to evaluate the filling effect of the missing values (Table 1).

A total of 120 deaths caused by AIDS-related diseases were contained in the case group of the nested case-control study. To ensure that all the subjects in the case group could have a matching control, PSM was applied at a ratio of 1:4 to determine the participants (a case was well matched by age and gender with 4 controls) ${ }^{[28]}$. Finally, 600 subjects were included in this study with 120 dead and 480 alive PLHIV who were separated into 120 blocks. 
Table 1

Sensitivity analysis in imputation for missing data

\begin{tabular}{|llll|}
\hline Variables & $\begin{array}{l}\text { Before imputation(mean } \pm \\
\text { standard deviation) }\end{array}$ & $\begin{array}{l}\text { After imputation(mean } \pm \\
\text { standard deviation) }\end{array}$ & $\begin{array}{l}P \\
\text { value }\end{array}$ \\
\hline Weight, $\mathrm{kg}$ & $64.8 \pm 10.2$ & $64.8 \pm 10.1$ & 0.9903 \\
\hline Height, cm & $172.0 \pm 6.1$ & $172.0 \pm 6.0$ & 0.9405 \\
\hline $\mathrm{BMI}, \mathrm{kg} / \mathrm{m} 2$ & $21.9 \pm 3.0$ & $21.8 \pm 3.0$ & 0.5320 \\
\hline $\begin{array}{l}\text { White blood cell count, } \\
10^{9} / \mathrm{L}\end{array}$ & $5.65 \pm 2.0$ & $5.65 \pm 2.0$ & 0.9950 \\
\hline Blood platelet, 109/L & $188.7 \pm 62.5$ & $188.7 \pm 62.4$ & 0.9884 \\
\hline Hemoglobin, g/L & $142.7 \pm 30.9$ & $142.7 \pm 30.8$ & 0.9729 \\
\hline Creatinine, mmol/L & $71.3 \pm 19.4$ & $71.3 \pm 19.3$ & 0.9817 \\
\hline Triglyceride, mmol/L & $1.7 \pm 2.3$ & $1.7 \pm 2.3$ & 0.8398 \\
\hline $\begin{array}{l}\text { Total cholesterol, } \\
\text { mmol/L }\end{array}$ & $4.3 \pm 1.3$ & $4.3 \pm 1.3$ & 0.7732 \\
\hline $\begin{array}{l}\text { Fasting plasma } \\
\text { glucose, mmol/L }\end{array}$ & $5.6 \pm 1.3$ & $5.6 \pm 1.3$ & 0.9293 \\
\hline $\begin{array}{l}\text { Aspartate } \\
\text { aminotransferase, } \mathrm{U} / \mathrm{L}\end{array}$ & $27.0 \pm 27.1$ & $27.1 \pm 27.1$ & 0.9891 \\
\hline $\begin{array}{l}\text { Alanine } \\
\text { aminotransferase, } \mathrm{U} / \mathrm{L}\end{array}$ & $30.2 \pm 29.2$ & $30.2 \pm 29.2$ & 0.9964 \\
\hline $\begin{array}{l}\text { Total bilirubin, } \\
\text { mmol/L }\end{array}$ & $12.0 \pm 6.2$ & $12.0 \pm 6.2$ & 0.9905 \\
\hline
\end{tabular}

\section{Establishment and validation of prediction model}

The patients were randomly split into a training set and a validation set at a ratio of 7:3. The comparability of the training set and validation set was then evaluated. Continuous variables with normal distribution were presented as mean \pm standard deviation, and t-tests were used to infer the differences between the training and validation sets. The continuous variables subjecting to skewed distribution were described using median (first quartile, second quartile). The Wilcoxon rank-sum tests were employed for comparisons. Frequency (ratio) was utilized to describe the characteristics of categorical variables, and comparisons between the two sets were performed using chi-square tests or Fisher's exact tests.

Then the data in the training set were used to fit a model and the data in validation set were applied to evaluate the efficacy of the model. Based on the data in the training set, a univariate Cox regression analysis was performed on the variables. P-values of the variables were calculated based on the univariate Cox proportion hazard regression model. The variables with p-values less than or equal to 0.2 
were included in a multivariate Cox proportion hazard regression model. After multivariate analysis, the factors with $\mathrm{p}$-value less than or equal to 0.05 were included in a prediction model. According to Occam's

Razor, the model with the fewest variables is the best ${ }^{[29]}$. Finally, we combined the statistically significant risk factors with professionally significant factors, such as the difficulty of index measurement, the cost of measurement and the difficulty of application, to determine the predictive factors and select a prediction model with better predictive performance.

The repeatability and extrapolation of an established prediction model should be evaluated to assess its performance. A strict evaluation of the prediction model should include internal validation and external validation. The internal validation is performed using the same dataset as the training set. This study employed the bootstrap resampling ${ }^{[30]}$ for internal validation because there lacked extra data to verify the model. The 1,000 resampling performances of the model were averaged as the internal validation performance.

Discrimination and calibration are the two most common evaluation indicators. The discrimination of the prediction model is quantified using the area under the curve (AUC) and C-Index. The C-Index value ranges from 0 to 1 . The closer $C$-Index is to 1 , the better the discrimination of the model is. A C-Index of 0.5 indicates that the model has no predictive ability. When $\mathrm{C}$-Index is less than 0.5 , the model prediction is contrary to the actual results. In general, a C-Index of 0.7 indicates a good prediction performance of the model. However, discrimination cannot reflect whether the estimate of absolute risk of prediction model is accurate or not, because it is only based on risk scores or the ranking of prediction probabilities. Therefore, calibration, a more accurate indicator, is needed to qualify the prediction model. In this study, the calibration of the model was evaluated using the calibration curve.

We sorted the predicted probabilities of all participants from the smallest to the largest, and divided the patients into ten equal parts.

The average predicted probability of patients in each divided part was used as $\mathrm{x}$-axis and the proportion of actual events as $y$-axis. Ideally, the calibration graph was a straight line with an intercept of 0 and a slope of 1 . The predictive ability of the model was also evaluated using decision curve analysis (DCA).

Integrated discrimination improvement (IDI), net reclassification index or improvement (NRI) and other indicators that are used to compare models or evaluate the increase in predictive performance of individual predictors were not discussed in the present study.

\section{Presentation of nomogram}

The prediction model was visualized and presented by a nomogram. To calculate the score of each variable in each level, a scoring standard was developed based on the standard regression coefficients of all variables. Then using the scores of these factors, a total score was calculated to indicate the survival probability of each patient. 
All data analyses and figures were made using R software version 3.6.3. All hypothesis tests were twosided, with an a level of 0.05 .

\section{Results}

\section{Establishment of prediction model}

In this PSM based nested case-control study, the characteristics of the 600 PLHIV (420 from the training set and 180 from the validation set) revealed that both sets were similar in all variables (Table 2). 
Table 2

Baseline demographics and clinical characteristics of patients in the training set and the validation set Variable $\begin{array}{ll}\text { Training set }(\mathrm{N}=420) & \begin{array}{l}\text { Validation set }(\mathrm{N}= \\ 180)\end{array}\end{array}$

$P$ value

\section{Continuous variables}

\begin{tabular}{|c|c|c|c|}
\hline Age, year & $50.00(40.00,58.00)$ & $49.00(38.00,57.00)$ & 0.2229 \\
\hline Interval from onset to diagnosis, day & $52.00(26.00,157.00)$ & $54.00(28.50,178.00)$ & 0.4366 \\
\hline Alanine aminotransferase (ALT), U/L & $22.20(16.00,34.95)$ & $24.00(15.40,35.00)$ & 0.9783 \\
\hline $\begin{array}{l}\text { Aspartate aminotransferase (AST), } \\
\mathrm{U} / \mathrm{L}\end{array}$ & $23.50(18.55,31.80)$ & $22.82(18.50,34.30)$ & 0.9426 \\
\hline Body mass index, $\mathrm{kg} / \mathrm{m}^{2}$ & $21.97(20.09,23.88)$ & $22.01(19.32,23.88)$ & 0.5243 \\
\hline CD4 + T-lymphocyte count, cells $/ \mu \mathrm{L}$ & $256.50(117.50,389.50)$ & $264.50(110.50,370.00)$ & 0.7490 \\
\hline Total cholesterol, $\mathrm{mmol} / \mathrm{L}$ & $4.09(3.66,4.81)$ & $4.01(3.64,4.77)$ & 0.5960 \\
\hline Creatinine, $\mu \mathrm{mol} / \mathrm{L}$ & $70.20(61.00,76.85)$ & $67.75(59.30,76.05)$ & 0.2276 \\
\hline Fasting plasma glucose, $\mathrm{mmol} / \mathrm{L}$ & $5.62(5.09,6.18)$ & $5.49(4.97,6.00)$ & 0.0524 \\
\hline Haemoglobin, g/L & $135.50(116.00,151.00)$ & $138.00(120.50,151.00)$ & 0.4300 \\
\hline Blood platelet, $10^{9} / \mathrm{L}$ & $165.50(128.00,203.50)$ & $171.50(139.00,216.00)$ & 0.1750 \\
\hline Total bilirubin, $\mu \mathrm{mol} / \mathrm{L}$ & $10.30(7.60,13.40)$ & $10.30(7.90,13.60)$ & 0.7822 \\
\hline Triglyceride, $\mathrm{mmol} / \mathrm{L}$ & $1.43(1.00,2.00)$ & $1.43(1.10,2.00)$ & 0.6682 \\
\hline White blood cell, $10^{9} / \mathrm{L}$ & $5.03(3.90,6.40)$ & $5.15(4.07,6.31)$ & 0.6936 \\
\hline \multicolumn{4}{|l|}{ Discrete variables } \\
\hline \multicolumn{4}{|l|}{ Gender } \\
\hline Male & $375(89.29)$ & 164(91.11) & 0.4978 \\
\hline Female & $45(10.71)$ & $16(8.89)$ & \\
\hline \multicolumn{4}{|l|}{ Hepatitis B Virus } \\
\hline Negative & $387(92.14)$ & $167(92.78)$ & 0.7888 \\
\hline Positive & $33(7.86)$ & $13(7.22)$ & \\
\hline \multicolumn{4}{|l|}{ Hepatitis C Virus } \\
\hline Negative & $408(97.14)$ & $175(97.22)$ & 0.9572 \\
\hline Positive & $12(2.86)$ & $5(2.78)$ & \\
\hline
\end{tabular}




\begin{tabular}{|c|c|c|c|}
\hline Variable & Training set $(\mathrm{N}=420)$ & $\begin{array}{l}\text { Validation set }(\mathrm{N}= \\
\text { 180) }\end{array}$ & $\begin{array}{l}P \\
\text { value }\end{array}$ \\
\hline \multicolumn{4}{|l|}{ Marital status } \\
\hline Unmarried & $80(19.05)$ & $41(22.78)$ & 0.2967 \\
\hline Married & $340(80.95)$ & 139(77.22) & \\
\hline \multicolumn{4}{|l|}{ Shingles } \\
\hline No & $375(89.29)$ & $160(88.89)$ & 0.8860 \\
\hline Yes & $45(10.71)$ & $20(11.11)$ & \\
\hline \multicolumn{4}{|l|}{ Infection route } \\
\hline Homosexual transmission & $211(50.24)$ & $94(52.22)$ & 0.6772 \\
\hline Heterosexual transmission & $148(35.24)$ & $57(31.67)$ & \\
\hline Other transmission & $61(14.52)$ & $29(16.11)$ & \\
\hline \multicolumn{4}{|l|}{ Baseline Tuberculosis } \\
\hline No & $411(97.86)$ & $173(96.11)$ & 0.2238 \\
\hline Yes & $9(2.14)$ & $7(3.89)$ & \\
\hline \multicolumn{4}{|l|}{ WHO clinical stage } \\
\hline I, II & $193(45.95)$ & $79(43.89)$ & 0.6571 \\
\hline III & 104(24.76) & $51(28.33)$ & \\
\hline IV & $123(29.29)$ & $50(27.78)$ & \\
\hline \multicolumn{4}{|c|}{ Continuous or intermittent fever } \\
\hline No & $382(90.95)$ & $163(90.56)$ & 0.8773 \\
\hline Yes & $38(9.05)$ & $17(9.44)$ & \\
\hline \multicolumn{4}{|c|}{ Continuous diarrhea (> one month) } \\
\hline No & $391(93.10)$ & 169(93.89) & 0.7210 \\
\hline Yes & $29(6.90)$ & $11(6.11)$ & \\
\hline
\end{tabular}

In the univariate Cox regression analysis of the training set, infection route, TB, WHO clinical stage, CD4, $\mathrm{BMI}, \mathrm{WBC}, \mathrm{HB}, \mathrm{CR}, \mathrm{TC}, \mathrm{GLU}, \mathrm{AST}$ and ALT were detected to be statistically related to the mortality of PLHIV (Table 3). Variables with p-value less than or equal to 0.2 in the univariate analysis were included in the multivariate Cox hazard regression model. CD4, BMI, CR and GLU were found linked to HIV/AIDS-related death. In order to establish an optimal prediction model, the individual and combined performance of 
these four factors were then evaluated using ROC analysis and C-Index. As shown in Fig. 2A, the individual AUCs of CD4, BMI, CR, and GLU in the training set were $0.796,0.689,0.524$, and 0.689 , respectively. The AUC of combine $1(\mathrm{CD} 4+\mathrm{BMI}+\mathrm{CR}+\mathrm{GLU})$ was 0.833 , and the AUC of combine 2 (CD4 + $\mathrm{BMI}+\mathrm{GLU}$ ) was 0.826 . To compare the predictive performances of combine 1 and combine 2 , their corresponding C-Indexes were calculated, and the results were $0.797(95 \% \mathrm{Cl}: 0.745,0.849)$ and 0.793 ( $95 \% \mathrm{Cl}: 0.740,0.846)$, indicating both models had a prediction accuracy of around $80 \%$. Besides, no statistically significant difference in the $C$-Indexes between combine 1 and combine 2 model was observed $(P=0.9160)$ (Fig. 3A). The discrimination between the two models was not large, but combine 2 involved fewer variables. Thus, combine 2 model was chosen and the three variables CD4, BMI and GLU were preliminarily selected to construct a prediction model of three-year and five-year survival probabilities of PLHIV after ART. 
Table 3

Univariate and Multivariate Cox hazards analysis of the training set

\begin{tabular}{|c|c|c|c|c|}
\hline \multirow[t]{2}{*}{ Variables } & \multicolumn{2}{|l|}{ Univariate } & \multicolumn{2}{|l|}{ Multivariate } \\
\hline & $\mathrm{HR}(95 \% \mathrm{Cl})$ & $P$ value & AHR $(95 \% \mathrm{Cl})$ & $P$ value \\
\hline Female & $\begin{array}{l}1.212(0.604 \\
2.435)\end{array}$ & 0.588 & & \\
\hline Marital Status (Married) & $\begin{array}{l}1.159 \text { (0.637, } \\
2.109)\end{array}$ & 0.629 & & \\
\hline \multicolumn{5}{|l|}{ Infection route } \\
\hline $\begin{array}{l}\text { Homosexual } \\
\text { transmission }\end{array}$ & Ref & Ref & Ref & Ref \\
\hline Heterosexual transmission & $\begin{array}{l}1.235(0.743 \\
2.053)\end{array}$ & 0.415 & $\begin{array}{l}1.360(0.790 \\
2.343)\end{array}$ & 0.268 \\
\hline Other transmission & $\begin{array}{l}1.535(0.818 \\
2.879)\end{array}$ & $0.182 \#$ & $\begin{array}{l}0.990 \\
1.953)\end{array}(0.502$, & 0.977 \\
\hline Baseline Tuberculosis & $\begin{array}{l}2.309(0.727 \\
7.336)\end{array}$ & $0.156 \#$ & $\begin{array}{l}1.995(0.604 \\
6.585)\end{array}$ & 0.257 \\
\hline HBV (Positive) & $\begin{array}{l}1.715(0.539 \\
5.458)\end{array}$ & 0.361 & & \\
\hline HCV (Positive) & $\begin{array}{l}1.911(0.265 \\
13.767)\end{array}$ & 0.520 & & \\
\hline $\begin{array}{l}\text { Continuous diarrhea (> one } \\
\text { month) }\end{array}$ & $\begin{array}{l}1.424(0.653 \\
3.103)\end{array}$ & 0.374 & & \\
\hline Continuous or intermittent fever & $\begin{array}{l}1.346(0.670 \\
2.704)\end{array}$ & 0.404 & & \\
\hline Shingles & $\begin{array}{l}1.276(0.655 \\
2.486)\end{array}$ & 0.473 & & \\
\hline \multicolumn{5}{|l|}{ WHO clinical stage } \\
\hline I, II & Ref & Ref & Ref & Ref \\
\hline III & $\begin{array}{l}1.377(0.713 \\
2.658)\end{array}$ & 0.340 & $\begin{array}{l}0.702 \text { (0.358, } \\
1.376)\end{array}$ & 0.303 \\
\hline IV & $\begin{array}{l}3.325(1.956 \\
5.651)\end{array}$ & $\begin{array}{l}8.99 \mathrm{e}- \\
06^{\star \star \star}\end{array}$ & $\begin{array}{l}0.646(0.343 \\
1.218)\end{array}$ & 0.177 \\
\hline Age, year & $\begin{array}{l}1.008(0.9907 \\
1.026)\end{array}$ & 0.361 & & \\
\hline
\end{tabular}




\begin{tabular}{|c|c|c|c|c|}
\hline \multirow[t]{2}{*}{ Variables } & \multicolumn{2}{|l|}{ Univariate } & \multicolumn{2}{|l|}{ Multivariate } \\
\hline & $\mathrm{HR}(95 \% \mathrm{Cl})$ & $P$ value & AHR $(95 \% \mathrm{Cl})$ & $P$ value \\
\hline $\begin{array}{l}\text { Interval from onset to diagnosis, } \\
\text { day }\end{array}$ & $1(0.999,1.000)$ & 0.965 & & \\
\hline $\begin{array}{l}\text { CD } 4+\text { T-lymphocyte cell count, } \\
\text { cells/ } \mu \mathrm{L}\end{array}$ & $\begin{array}{l}0.994(0.992, \\
0.996)\end{array}$ & $\begin{array}{l}1.19 \mathrm{e}- \\
11^{\star \star \star}\end{array}$ & $\begin{array}{l}0.994(0.992 \\
0.996)\end{array}$ & $\begin{array}{l}4.29 \mathrm{e}- \\
08^{\star \star \star}\end{array}$ \\
\hline $\mathrm{BMI}, \mathrm{kg} / \mathrm{m} 2$ & $\begin{array}{l}0.817(0.757 \\
0.882)\end{array}$ & $\begin{array}{l}2.19 \mathrm{e}- \\
07^{\star \star \star}\end{array}$ & $\begin{array}{l}0.873(0.797 \\
0.957)\end{array}$ & $0.004^{* *}$ \\
\hline White blood cell count, $10^{9} / \mathrm{L}$ & $\begin{array}{l}0.887(0.782 \\
1.006)\end{array}$ & $0.061 \#$ & $\begin{array}{l}0.963(0.895 \\
1.037)\end{array}$ & 0.320 \\
\hline Blood platelet, $10^{9} / \mathrm{L}$ & $\begin{array}{l}0.998(0.994 \\
1.002)\end{array}$ & 0.229 & & \\
\hline Hemoglobin, $g / L$ & $\begin{array}{l}0.978(0.972 \\
0.984)\end{array}$ & $\begin{array}{l}3.69 \mathrm{e}- \\
11^{\star \star \star}\end{array}$ & $\begin{array}{l}0.994(0.984 \\
1.004)\end{array}$ & 0.260 \\
\hline Creatinine, $\mu \mathrm{mol} / \mathrm{L}$ & $\begin{array}{l}1.002(1.000 \\
1.005)\end{array}$ & $0.0528 \#$ & $\begin{array}{l}1.003(1.001 \\
1.006)\end{array}$ & $0.019 *$ \\
\hline Triglyceride, $\mathrm{mmol} / \mathrm{L}$ & $\begin{array}{l}1.001(0.941 \\
1.064)\end{array}$ & 0.982 & & \\
\hline Total cholesterol, mmol/L & $\begin{array}{l}0.772(0.600 \\
0.994)\end{array}$ & $0.045^{\star}$ & $\begin{array}{l}0.997(0.764 \\
1.303)\end{array}$ & 0.985 \\
\hline Fasting blood glucose, $\mathrm{mmol} / \mathrm{L}$ & $\begin{array}{l}0.634(0.507 \\
0.794)\end{array}$ & $\begin{array}{l}6.92 \mathrm{e}- \\
05^{\star \star \star}\end{array}$ & $\begin{array}{l}0.724(0.557 \\
0.941)\end{array}$ & $0.016^{*}$ \\
\hline $\begin{array}{l}\text { Aspartate aminotransferase } \\
\text { (AST), U/L }\end{array}$ & $\begin{array}{l}1.011(1.004 \\
1.017)\end{array}$ & $\begin{array}{l}8.50 \mathrm{e}- \\
04 \star \star \star\end{array}$ & $\begin{array}{l}1.004(0.992 \\
1.017)\end{array}$ & 0.493 \\
\hline $\begin{array}{l}\text { Alanine aminotransferase (ALT), } \\
\mathrm{U} / \mathrm{L}\end{array}$ & $\begin{array}{l}1.008(1.000 \\
1.017)\end{array}$ & $0.047^{\star}$ & $\begin{array}{l}1.003(0.989 \\
1.017)\end{array}$ & 0.709 \\
\hline Total bilirubin, mmol/L & $\begin{array}{l}0.985(0.941 \\
1.031)\end{array}$ & 0.526 & & \\
\hline
\end{tabular}

\section{Validation of prediction model}

In order to verify the efficacy of the model in predicting the survival probability of PLHIV, bootstrap resampling was used for internal validation of the model. In the validation set, the AUCs of CD4, BMI, CR, and GLU were $0.731,0.729,0.535$ and 0.673 in the ROC analysis chart (Fig. 2B). The AUC of combine 1 achieved 0.751 , and the AUC of combine 2 (prediction model) was 0.750 . The C-Indexes of combine 1 $(0.776 ; 95 \% \mathrm{Cl}: 0.712,0.840)$ and combine $2(0.776 ; 95 \% \mathrm{Cl}: 0.711,0.839)$ were similar and the difference was not statistically significant $(P=0.999)$, which showed that the discrimination of combine 1 and combine 2 (prediction model) was not very large (Fig. 3B). The calibration curve also exhibited a high 
consistency in predicting the survival probability of PLHIV (especially in the first three years after ART initiation) (Fig. 4).

As shown in Fig. 5, in both the training set and the validation set, the prediction model (combine 2) showed better performance, thus ensuring the maximum clinical benefits. Overall, the DCA curve demonstrated that the prediction model (combine 2) could make valuable and profitable judgements. In addition, among the four detected factors, CD4 was more beneficial than the other three routine clinical laboratory indicators in predicting the three-year and five-year survival probabilities of PLHIV.

\section{Performance of nomogram}

A nomogram was drawn according to the determined prediction model. As seen in Fig. 6, each selected predictor was assigned a corresponding score according to its value in the nomogram based on the established prediction model. Then a vertical line perpendicular to the Point axis was drawn from this point. The intersection point on the Point axis represented the score under the determined value of the predictor. For example, when CD 4 was 1200 cells/ $\mu \mathrm{L}$, the score was 0 point; when BMI was $12 \mathrm{~kg} / \mathrm{m}^{2}$, the score was 39 points. By analogy, the score corresponding to each predictor of each patient could be determined, and the total score was the sum of the scores of all predictors. Similarly, after the total score was calculated, a vertical line was drawn from the point of the patient's total score on the Total Points axis to the axis of survival probability (such as three-year survival probability or five-year survival probability). The intersection point on the axis of survival probability represented the patient's three-year or five-year survival probability.

\section{Discussion}

Although the survival probability of PLHIV has been improved significantly with the promotion of free ART, an in-time and accurate prediction of survival probability of PLHIV is still necessary as an HIV/AIDS management guideline for health providers. For clinicians and disease control personnel, it can also benefit the personalized management of PLHIV and the allocation of the limited medical resources ${ }^{[26]}$.

For prognosis, due to a longitudinal temporal logic between predictors and outcome, cohort study is applied to analyze the data and fit a prognostic model. Randomized controlled clinical trials are considered as a prospective cohort study with more rigorous inclusion criteria, which therefore can be used to establish a prognostic model. However, it has limitations in extrapolation. Due to the population selection bias and information bias, retrospective cohort studies are not suitable for constructing a prognostic model, while nested case-control or case cohort studies are more economical and feasible for studies with rare outcomes or expensive predictive factor measurements. Based on this nested casecontrol study from an HIV/AIDS ART cohort in Nanjing, the relationship between routine laboratory indicators and the survival probability of PLHIV was evaluated. A prognostic model (including CD4, BMI and GLU) with satisfactory discrimination and calibration was developed to predict the three-year and 
five-year survival probabilities of PLHIV receiving ART. Then the result of this prognostic model was shown in the form of a nomogram.

Nomogram is simple, direct and effective in predicting the prognosis of PLHIV and can be easily understood by medical workers ${ }^{[24]}$. In this study, the multivariate Cox proportional hazard regression model indicated that the four factors (CD4, BMI, CR and GLU) were associated with the HIV/AIDS-related survival time. To overcome the limitation of a single predictor and simplify the prediction procedure, three detected factors (CD4, BMI and GLU) were combined to construct a prognostic model to predict the threeyear and five-year survival probabilities of ART-treated PLHIV, which exhibited a high consistency.

Some clinical indicators (such as WHO clinical stage) with close association with PLHIV survival rate ${ }^{\text {[13] }}$ were not included in the nomogram because the laboratory indicators (such as CD4) were more sensitive in predicting survival rate of PLHIV than the clinical indicators. In recent years, many researchers have reported that some laboratory indicators are connected with the survival rate of PLHIV. In this study, CD4, $\mathrm{BMI}$ and GLU were significantly correlated with the survival rate of PLHIV and showed good consistency with these published studies ${ }^{[10,16,21,26]}$.

An obesity paradox can be seen in this predictive nomogram of PLHIV, where those with high BMI had a low risk of death. This maybe that the protective effect of BMI help preserve the immune system response and slower the progression of HIV ${ }^{[31]}$. There is some evidence that a higher BMI is associated with more robust CD $4+$ T-lymphocyte cell recovery in ART-treated patients ${ }^{[32]}$. Previous studies also suggested that the immune reconstitution on ART was often highest among patients classified as overweight ${ }^{[33]}$.

DCA is commonly applied to assess the efficacy of specific clinical prediction models ${ }^{[34]}$. In this study, DCA was used to assess the potential clinical benefits of nomogram, which revealed that nomogram was more effective and accurate than a single indicator in forecasting the survival rate of PLHIV.

The present model has a limitation: it was established based on only a small number of easy-to-collect and low-cost predictors due to the underdeveloped technology in the past. Yet, with the advancement of economy and technology, clinical prediction models that involve a larger number of data (big data) will be developed. Hopefully, more complex models and algorithms based on machine learning and artificial intelligence can provide more accurate results for the benefits of medical workers, PLHIV and medical decision makers.

\section{Declarations}

\section{Ethics approval and consent to participate}

The data were extracted from the Nanjing AIDS Prevention and Control Information System (AIDS-PCIS), which was established by the China Center for Disease Control and Prevention (CCDC). All the methods carried out in our study are accorded with relevant guidelines. The AIDS-PCIS protocol was approved by 
the institutional review boards at the CCDC. Informed consent was obtained from the subjects before their enrollments. The ethical approval for the study was also obtained from the Ethics Review Board of Nanjing Center for Disease Control and Prevention and the ethical committee of Nanjing Medical University ("F", "CH", "Nanjing Med U", "FWA00001501", "NANJING", 11/21/2004). I have read and have abided by the statement of ethical standards for manuscripts submitted to BMC Public Health.

\section{Consent for publication}

Not applicable.

\section{Availability of data and materials}

The datasets used and/or analysed during the current study are available from the corresponding author on reasonable request.

\section{Competing interests}

All authors declare that they have no conflict of interest or financial conflicts to disclose.

\section{Funding}

This work was supported in part by the National Natural Science Foundation of China (82073673, 91846302), Nanjing key medical science and technology development projects (ZKX19050), and the National S\&T Major Project Foundation of China (2017ZX10201101, 2018ZX10715002).

\section{Authors' contributions}

GF, $L W^{6}$, and $\mathrm{ZL}$ curated and provided data. $\mathrm{ZL}$ and JX screened the data. $\mathrm{LL}$ and GF performed laboratory tests. FJ, YX, LL, KW and LW ${ }^{4}$ performed data analysis. FJ and $Y X$ drafted the manuscript. NW and $\mathrm{HX}$ provided guidance for epidemiological analysis throughout the study. ZZ and ZP adjusted the research framework, provided financial support, and revised the manuscript. All authors read and approved the final manuscript.

\section{Acknowledgements}

The authors thank all the study participants for their contributions and the staff at all participating institutions for their support.

\section{References}

1. Zayeri F, Ghane E T, Borumandnia N. Assessing the trend of HIV/AIDS mortality rate in Asia and North Africa: an application of latent growth models[J]. Epidemiology \& Infection, 2016, 144(3): 548555 . 
2. Zhang $F$ J, Jennifer $P$, Lan $Y$, et al. Current progress of China's free ART program[J]. Cell research, 2005, 15(11): 877-882.

3. Bansi L, Gazzard B, Post F, et al. Biomarkers to monitor safety in people on art and risk of mortality[J]. JAIDS Journal of Acquired Immune Deficiency Syndromes, 2012, 60(1): 51-58.

4. Wang C W, Chan C L W, Ho R T H. HIV/AIDS-related deaths in China, 2000-2012[J]. AIDS care, 2015, 27(7): 849-854.

5. Ning S P, Xue Z D, Wei J, et al. HIV/AIDS related mortality in southern Shanxi province and its risk factors[J]. Chinese Journal of Epidemiology, 2015, 36(3): 245-249.

6. Yoshikura H. Shift of HIV/AIDS Deaths to an Older Age and Gender Difference: Inferences Derived from the Vital Statistics of Japan[J]. Japanese journal of infectious diseases, 2019, 72(6): 359-367.

7. Tang H L, Hou L, Han J, Li J, et al. Effects of standardized follow-up program among newly diagnosed HIV/AIDS cases in 2010[J]. Chinese Journal of Epidemiology, 2016, 37(12): 1602-1607.

8. Li Y, Wang J, He S F, et al. Survival time of HIV/AIDS cases and related factors in Beijing, 19952015[J]. Chinese Journal of Epidemiology, 2017, 38(11): 1509-1513.

9. Zeng Y L, Tang H L, Li J M, et al. Survival analysis of people living with HIV/AIDS in Sichuan province, 1991-2017[J]. Chinese Journal of Epidemiology, 2019, 40(3): 309-314.

10. Zhang G, Gong Y, Wang Q, et al. Outcomes and factors associated with survival of patients with HIV/AIDS initiating antiretroviral treatment in Liangshan Prefecture, southwest of China: A retrospective cohort study from 2005 to 2013[J]. Medicine, 2016, 95(27).

11. Zhang N, Zhu X y, Wang G Y, et al. Survival status and influencing factors of HIV/AIDS on highly active anti-retrovial therapy in Shandong province[J]. Chinese Journal of Epidemiology, 2019, 40(1): 74-78.

12. Justice A C, Modur S, Tate J P, et al. Predictive accuracy of the Veterans Aging Cohort Study (VACS) index for mortality with HIV infection: a north American cross cohort analysis[J]. Journal of acquired immune deficiency syndromes (1999), 2013, 62(2): 149.

13. Silverman R A, John-Stewart G C, Beck I A, et al. Predictors of mortality within the first year of initiating antiretroviral therapy in urban and rural Kenya: A prospective cohort study[J]. PloS one, 2019, 14(10): e0223411.

14. Seyoum D, Degryse J M, Kifle Y G, et al. Risk factors for mortality among adult HIV/AIDS patients following antiretroviral therapy in Southwestern Ethiopia: an assessment through survival models[J]. International journal of environmental research and public health, 2017, 14(3): 296.

15. Misgina $\mathrm{K} \mathrm{H}$, Weldu M G, Gebremariam $\mathrm{T} \mathrm{H}$, et al. Predictors of mortality among adult people living with HIV/AIDS on antiretroviral therapy at Suhul Hospital, Tigrai, Northern Ethiopia: a retrospective follow-up study[J]. Journal of Health, Population and Nutrition, 2019, 38(1): 37.

16. Jiang J, Qin X, Liu H, et al. An optimal BMI range associated with a lower risk of mortality among HIV-infected adults initiating antiretroviral therapy in Guangxi, China[J]. Scientific reports, 2019, 9(1): $1-10$. 
17. Aziz N, Quint J J, Breen E C, et al. 30-year longitudinal study of hematological parameters of HIV-1 negative men participating in Los Angeles multicenter AIDS Cohort Study (MACS)[J]. Laboratory medicine, 2019, 50(1): 64-72.

18. Harris R J, Sterne J A C, Abgrall S, et al. Prognostic importance of anaemia in HIV-1 infected patients starting antiretroviral therapy: collaborative analysis of prospective cohort studies in industrialized countries[J]. Antiviral therapy, 2008, 13(8): 959.

19. Belperio P S, Rhew D C. Prevalence and outcomes of anemia in individuals with human immunodeficiency virus: a systematic review of the literature[J]. The American journal of medicine, 2004, 116(7): 27-43.

20. Camon S, Quiros C, Saubi N, et al. Full blood count values as a predictor of poor outcome of pneumonia among HIV-infected patients[J]. BMC infectious diseases, 2018, 18(1): 189.

21. Bisson G P, Ramchandani R, Miyahara S, et al. Risk factors for early mortality on antiretroviral therapy in advanced HIV-infected adults[J]. AIDS (London, England), 2017, 31(16): 2217.

22. Gardner L I, Holmberg S D, Williamson J M, et al. Development of proteinuria or elevated serum creatinine and mortality in HIV-infected women[J]. JAIDS Journal of Acquired Immune Deficiency Syndromes, 2003, 32(2): 203-209.

23. Driver T H, Scherzer R, Peralta C A, et al. Comparisons of creatinine and cystatin C for detection of kidney disease and prediction of all-cause mortality in HIV-infected women[J]. AIDS (London, England), 2013, 27(14): 2291.

24. Moons KG, Altman DG, Reitsma JB, loannidis JP, Macaskill P, Steyerberg EW, et al. Transparent Reporting of a multivariable prediction model for Individual Prognosis or Diagnosis (TRIPOD): explanation and elaboration. Ann Intern Med. 2015; 162(1):W1-73.

25. Park S Y. Nomogram: An analogue tool to deliver digital knowledge[J]. The Journal of thoracic and cardiovascular surgery, 2018, 155(4): 1793.

26. McNairy M L, Jannat-Khah D, Pape J W, et al. Predicting death and lost to follow-up among adults initiating antiretroviral therapy in resource-limited settings: Derivation and external validation of a risk score in Haiti[J]. PloS one, 2018, 13(8): e0201945.

27. Hou X, Wang D, Zuo J, et al. Development and validation of a prognostic nomogram for HIV/AIDS patients who underwent antiretroviral therapy: Data from a China population-based cohort[J]. EBioMedicine, 2019, 48: 414-424.

28. Benedetto U, Head S J, Angelini G D, et al. Statistical primer: propensity score matching and its alternatives[J]. European Journal of Cardio-Thoracic Surgery, 2018, 53(6): 1112-1117.

29. Van Den Berg H A. Occam's razor: from Ockham's via moderna to modern data science[J]. Science progress, 2018, 101(3): 261-272.

30. Efron B. Bootstrap Methods: Another Look at the Jackknife[J]. Annals of Statistics, 1979, 7(1): 1-26.

31. Shor-Posner G, Campa A, Zhang G, et al. When obesity is desirable: a longitudinal study of the Miami HIV-1-infected drug abusers (MIDAS) cohort[J]. Journal of acquired immune deficiency syndromes (1999), 2000, 23(1): 81-88. 
32. Koethe J R, Jenkins C A, Lau B, et al. Higher time-updated body mass index: association with improved CD4 + cell recovery on HIV treatment[J]. Journal of acquired immune deficiency syndromes (1999), 2016, 73(2): 197.

33. Koethe J R, Jenkins C A, Shepherd B E, et al. An optimal body mass index range associated with improved immune reconstitution among HIV-infected adults initiating antiretroviral therapy[J]. Clinical infectious diseases, 2011, 53(9): 952-960.

34. Kerr K F, Brown M D, Zhu K, et al. Assessing the clinical impact of risk prediction models with decision curves: guidance for correct interpretation and appropriate use[J]. Journal of Clinical Oncology, 2016, 34(21): 2534.

\section{Figures}
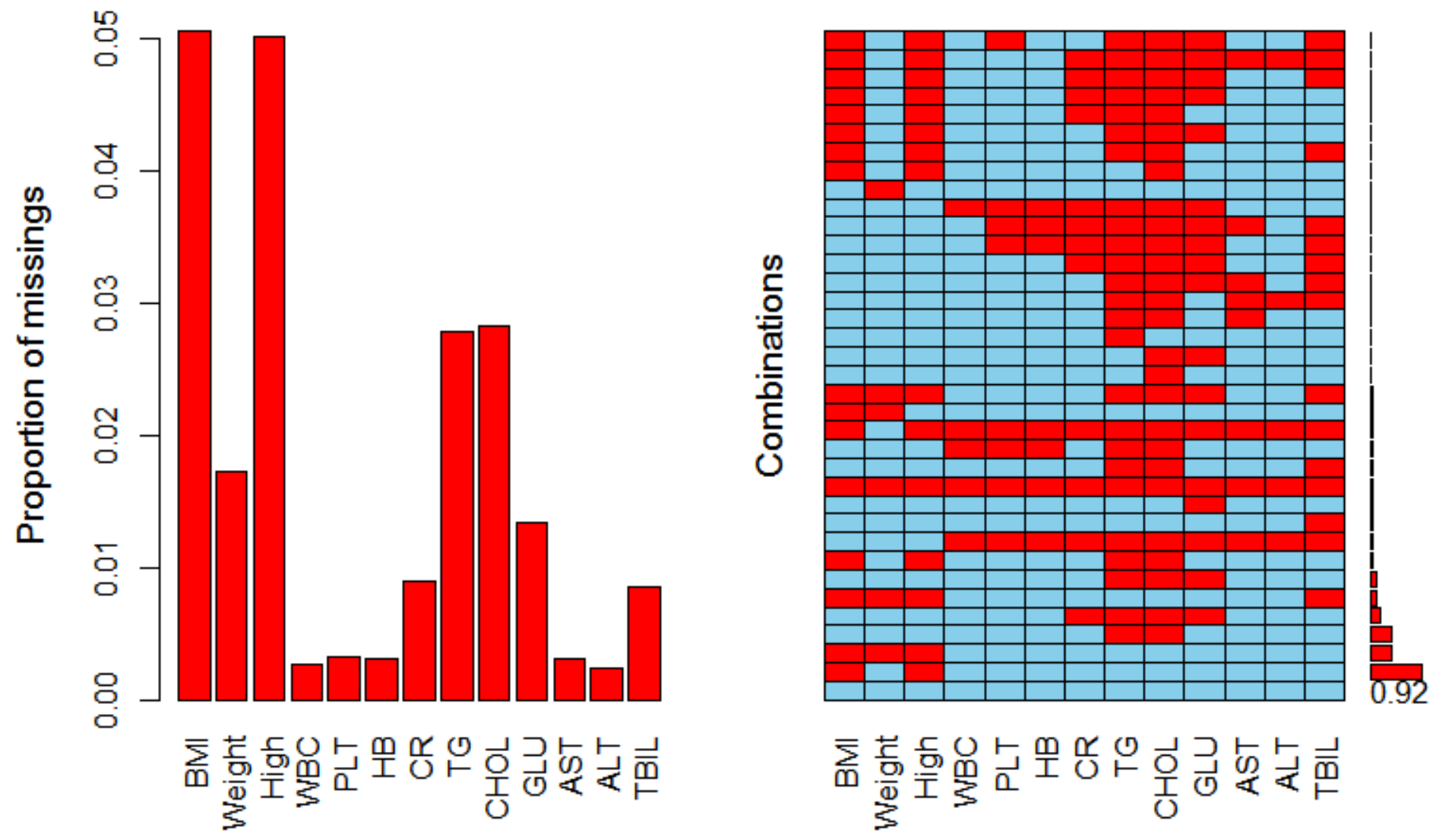

\section{Figure 1}

Proportion of missing values $(A)$ and combinations of missing values $(B)$ in training set 
A ROC curve for training set

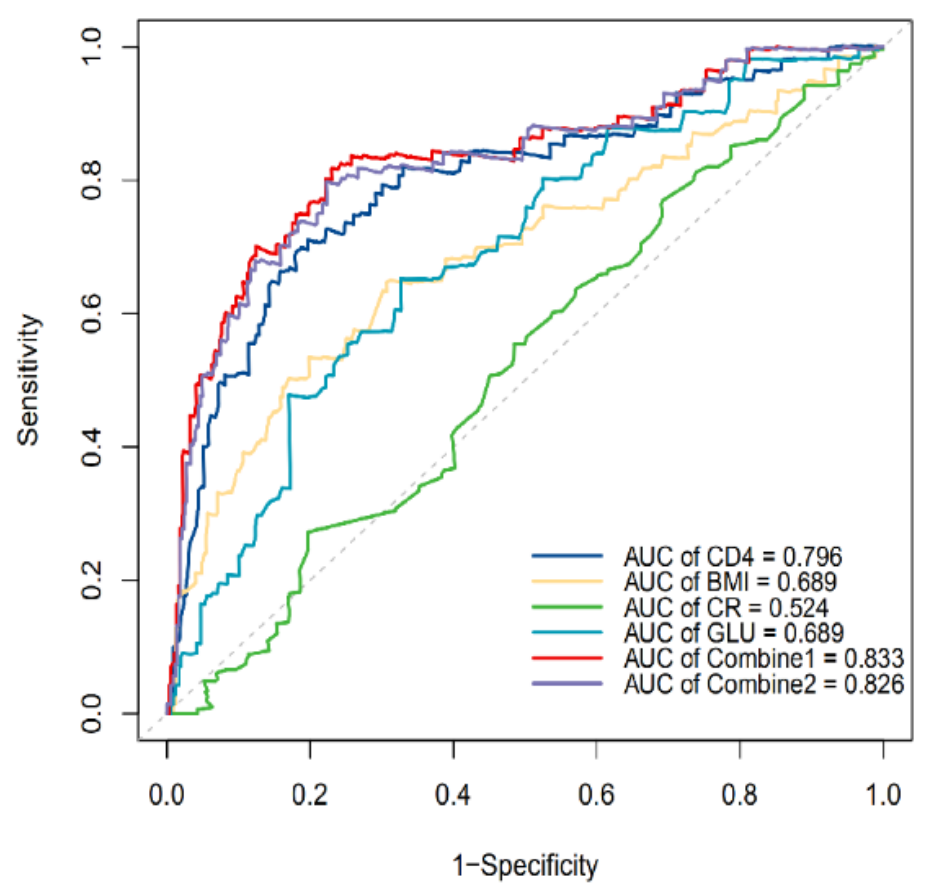

B

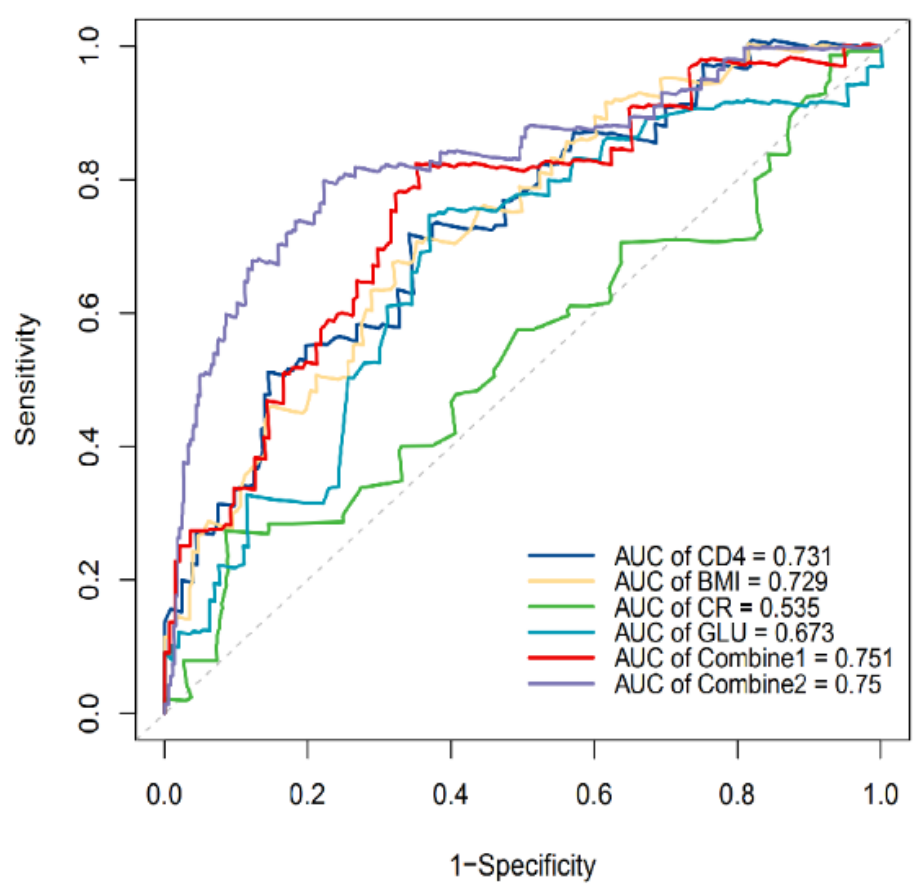

\section{Figure 2}

ROC curves of CD4, BMI, GLU, CR, combine 1 (CD4, BMI, CR, GLU) and combine 2 (CD4, BMI, GLU) in the training set $(A)$ and the validation set $(B)$
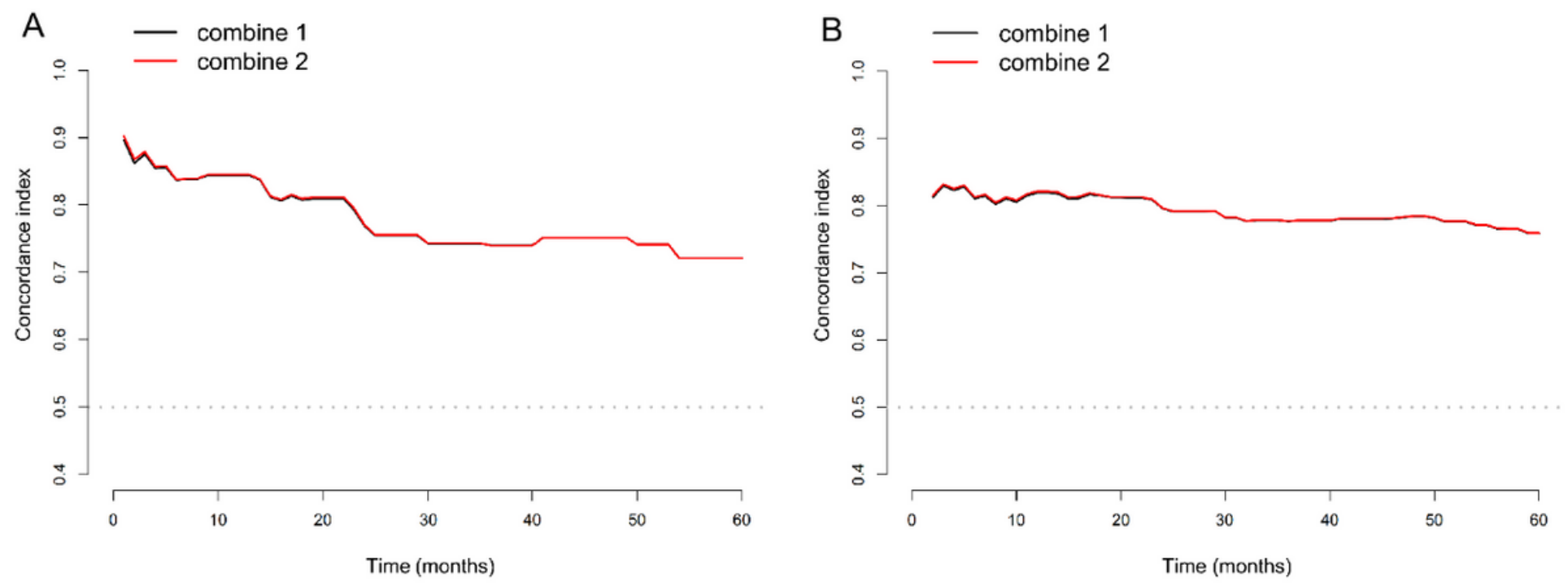

\section{Figure 3}

C-Indexes of combine 1 (CD4, BMI, CR, GLU) and combine 2 (CD4, BMI, GLU) in the training set (A) and the validation set $(B)$ 
A

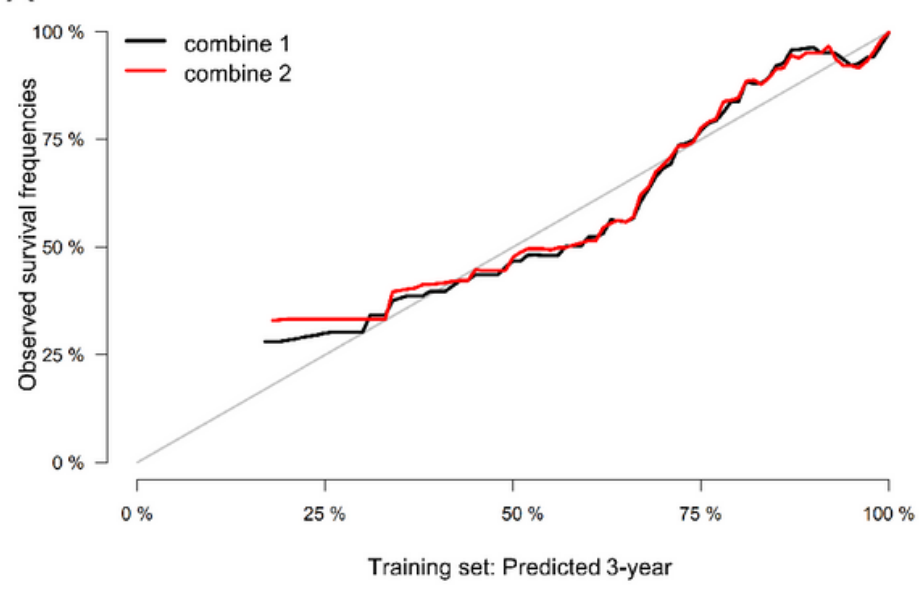

C

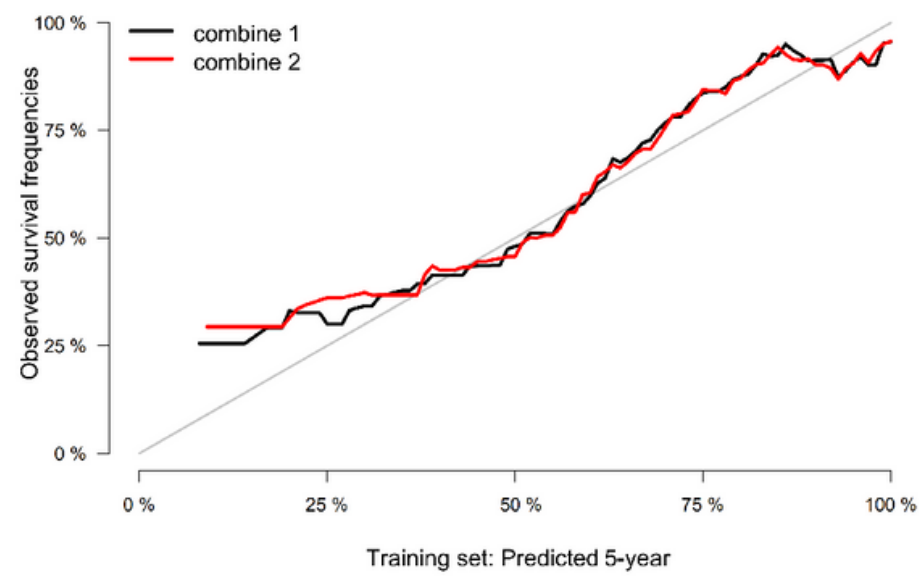

B

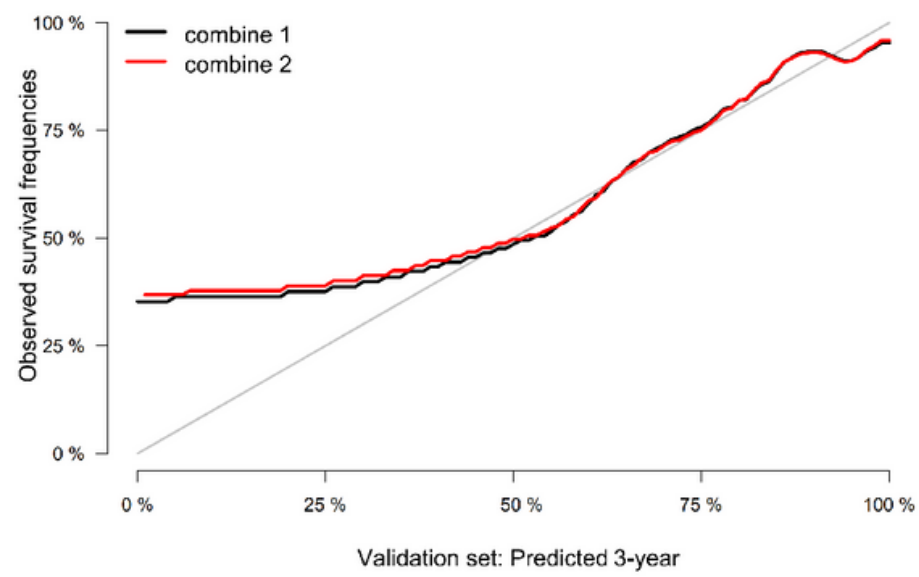

D

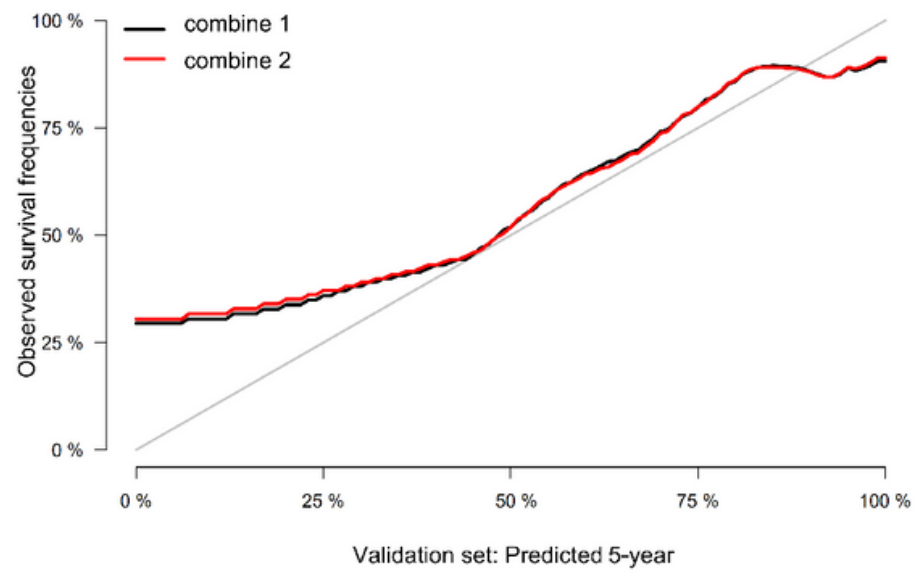

\section{Figure 4}

Calibration curves for predicting overall survival rate by combine 1 (CD4, BMI, CR, GLU) and combine 2 (CD4, BMI, GLU) in the training set and the validation set. Notes: Calibration curves for 3-year overall survival (A), 5-year overall survival (C) in the training set; calibration curves for 3-year overall survival (B), 5 -year overall survival (D) in the validation set. 
A

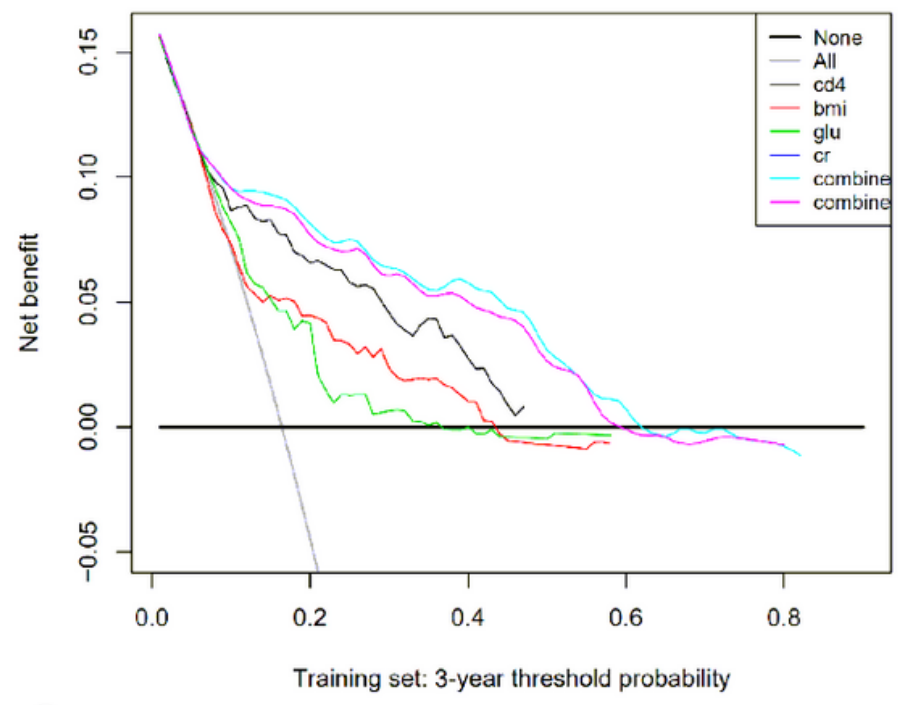

C

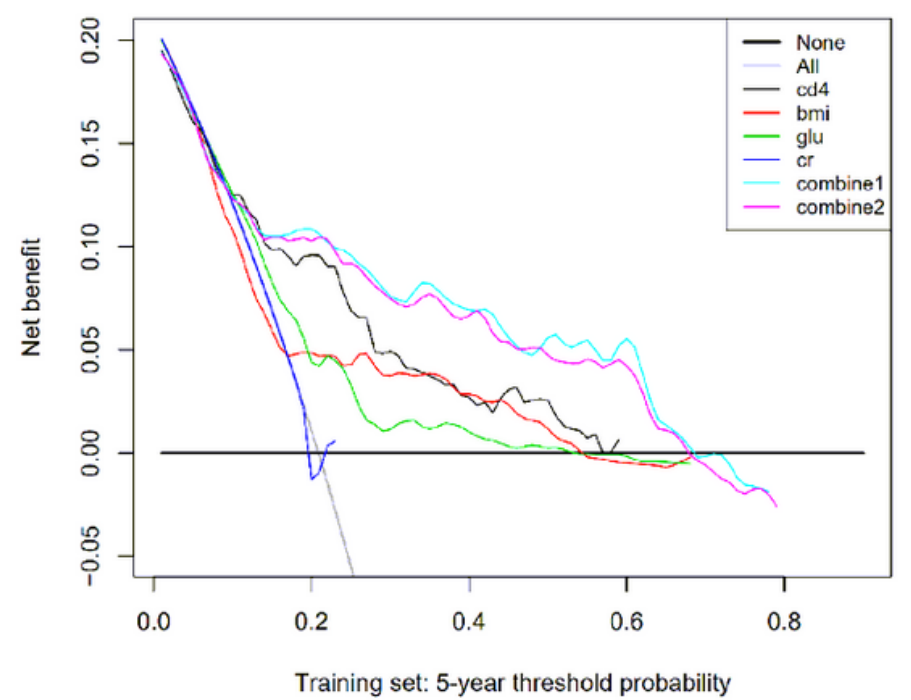

B

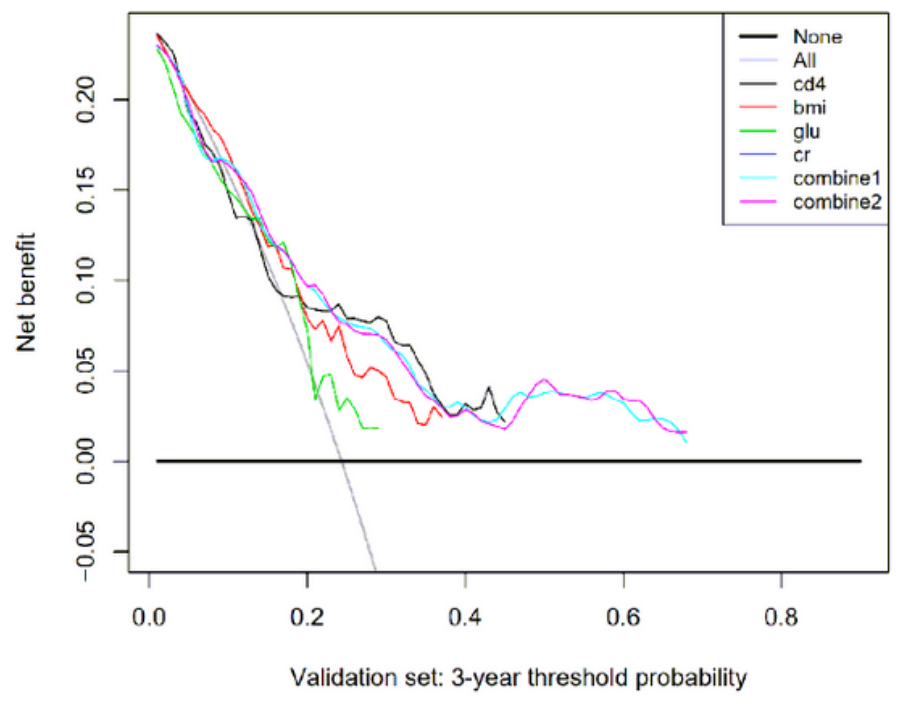

D

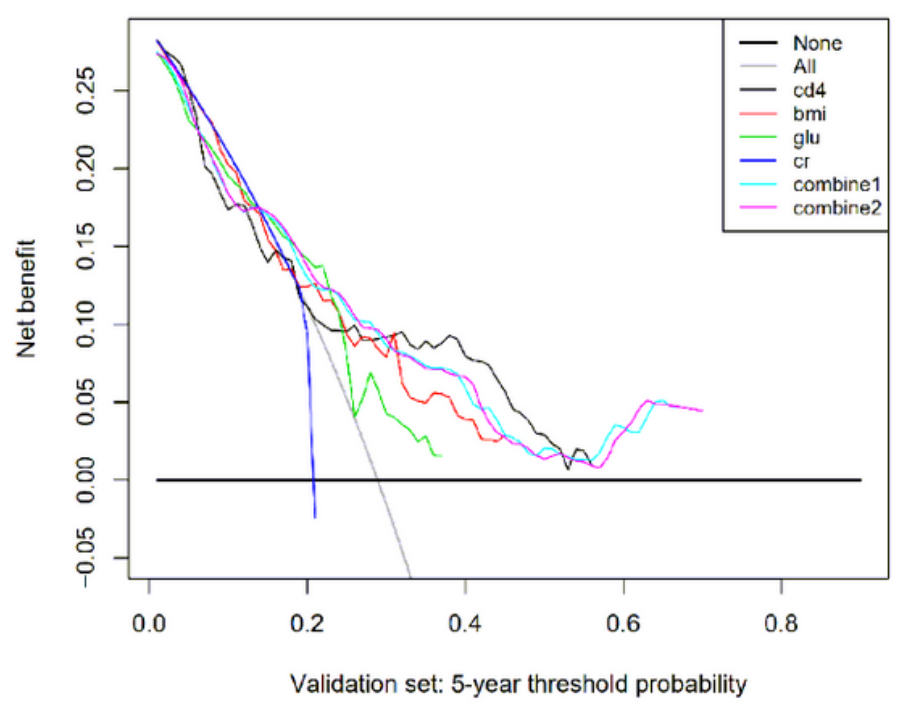

\section{Figure 5}

The Decision Curves Analysis curve of CD4, BMI, GLU, CR, combine 1 (CD4, BMI, CR, GLU) and combine 2 (CD4, BMI, GLU) in the training set and the validation set. Notes: The horizontal axis represents the threshold probability, the probability of whether a patient receives treatment. The vertical axis represents the net benefit rate after the advantages minus the disadvantages. Under the same threshold probability, a larger net benefit implies that patients can obtain the maximum benefit using this model. The closer the curve in the DCA graph is to the top, the higher the value of the model diagnosis is. 
Points

$\begin{array}{llllllllll}0 & 10 & 20 & 30 & 40 & 50 & 60 & 70 & 80 & 90\end{array}$

CD4

BMI

GLU

Total Points

Linear Predictor

3-year Survival Probability

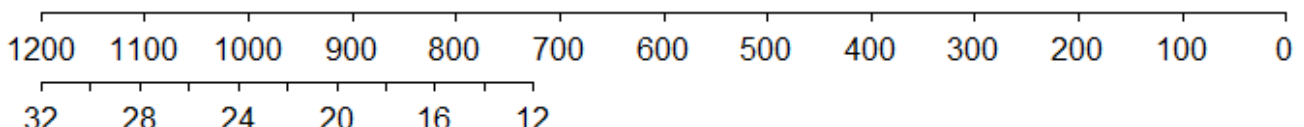

$\begin{array}{llllll}32 & 28 & 24 & 20 & 16 & 12\end{array}$

5-year Survival Probability

\begin{tabular}{|c|c|c|c|c|c|c|c|c|c|c|c|c|c|}
\hline 22 & 20 & 18 & 16 & 14 & 12 & & 10 & 8 & 6 & & 4 & 2 & \\
\hline \multirow[t]{3}{*}{0} & 20 & 40 & 60 & 80 & 10 & & 120 & 140 & & & 180 & 200 & 220 \\
\hline & & & & -6 & -5 & -4 & -3 & -2 & -1 & 0 & 1 & 2 & 3 \\
\hline & & & & & & & & & & 0.9 & & 0.50 .3 & \\
\hline
\end{tabular}

\section{Figure 6}

Nomogram of laboratory index for predicting HIV/AIDS-related survival of PLHIV after ART initiation

\section{Supplementary Files}

This is a list of supplementary files associated with this preprint. Click to download.

- DATAupload.csv 